Constança Simões Barbosa ${ }^{1}$ Ana Lúcia Coutinho Domingues 2 Frederico Abath 1

Silvia Maria Lucena Montenegro ${ }^{1}$

Ubiracy Guida ${ }^{3}$

Jefferson Carneiro 2

Barnabé Tabosa 1

Clarice N. Lins de Moraes 1

Vitorino Spinelli 2

\section{Epidemia de esquistossomose aguda na praia de Porto de Galinhas, Pernambuco, Brasil}

\author{
An outbreak of acute schistosomiasis at Porto \\ de Galinhas beach, Pernambuco, Brazil
}

\footnotetext{
1 Centro de Pesquisas Aggeu Magalhães,

Fundação Oswaldo Cruz. Campus da UFPE, Recife, PE 50670-420, Brasil.

cbarbosa@cpqam.fiocruz.br

2 Hospital das Clínicas,

Universidade Federal

de Pernambuco. Campus

da UFPE, Recife, PE

50670-420, Brasil.

3 Fundação Nacional de

Saúde. Av. Rosa e Silva 1480,

Recife, PE 50000-000, Brasil.
}

\begin{abstract}
We recently confirmed several cases of acute schistosomiasis in Porto de Galinhas beach, Northeast Brazil. A total of 662 patients were diagnosed by parasitological and clinical examinations. The infection likely occurred during the September 7 national holiday, when heavy rainfall flooded the Ipojuca River and people were infected when the water covered their yards. Families were continuously exposed to infection for a period of three weeks until the water had completely dried up. Previous investigation suggests that snail vectors were introduced as a result of landfill in marshy areas. The swamp-flooding of such areas facilitated the emergence of slums surrounded by snail breeding sites. Heavy rainfall caused open-air sewage ditches to overflow, allowing for infection of snails by Schistosoma mansoni. Thus, continuous floods were responsible for the spread of human infection. Clinical and laboratory results identified $62 \%$ of acute cases of S. mansoni. Complementary studies are being conducted to define the impact and epidemiological meaning of the acute schistosomiasis outbreak.
\end{abstract}

Key words Acute Schistosomiasis; Schistosomiasis Control; Schistosomiasis Outbreak

Resumo Este trabalho notifica a ocorrência de um surto de esquistossomose aguda na praia de Porto de Galinhas, Pernambuco, Brasil, quando 662 pessoas tiveram diagnóstico positivo para Schistosoma mansoni. A infecção humana em massa ocorreu no feriado de 7 de setembro, quando chuvas pesadas provocaram a enchente do rio Ipojuca que invadiu as residências. A maioria dos casos agudos foi representada por famílias de residentes locais que tiveram exposição diária às cercárias durante três semanas, até que as águas baixassem. O inquérito malacológico aponta para a possibilidade dos caramujos vetores terem sido introduzidos na localidade com os aterros realizados em quintais, onde vieram a se reproduzir em criadouros peridomiciliares. A infecção dos moluscos se deu a partir de vazamentos de fossas. Os resultados da clínica e do laboratório apontam para cerca de $62 \%$ de casos agudos. Estudos complementares estão sendo realizados, para a melhor compreensão deste evento epidemiológico de significativa magnitude para os órgãos de saúde pública e impacto para a população afetada.

Palavras-chave Esquistossomose Aguda; Controle da Esquistossomose; Surto de Esquistossomose 


\section{Introdução}

No Estado de Pernambuco, a esquistossomose é historicamente endêmica na região rural (Coutinho et al., 1997). A migração de trabalhadores rurais, aliada à gradual ocupação e modificação dos espaços urbanos, tem determinado a contínua expansão da esquistossomose, o estabelecimento de novos focos urbanos $\mathrm{e}$ de sucessivos relatos de casos agudos da doença em estados como Pernambuco (Barbosa et al., 1998), Ceará (Almeida et al., 1991), Minas Gerais (Barata et al., 2000), Sergipe (Silva et al., 2000) e São Paulo (Lima, 1995). Também vem se notando uma mudança no perfil epidemiológico da doença. Em área rurais, a esquistossomose se apresenta predominantemente sob a forma crônica, incidindo na classe social de baixa renda e tendo como vetor a Biomphalaria straminea. No litoral, a doença é representada por casos agudos em pessoas de classes média e alta, sendo o vetor a Biomphalaria glabrata (Barbosa et al., 2000).

A presente comunicação tem como objetivo notificar a ocorrência de um surto de esquistossomose aguda na praia de Porto de Galinhas, litoral sul do Estado de Pernambuco, quando 662 pessoas foram diagnosticadas com a doença; $62 \%$ das quais apresentando forma aguda da epidemia.

\section{Material e métodos}

Agentes de saúde da FUNASA (Fundação Nacional de Saúde) elaboraram croquis para as localidades de Merepe III, Salinas, Pantanal, Socó e Vila de Porto, que representam cerca de $70 \%$ da área habitada de Porto de Galinhas, com aproximadamente 3.000 moradores locais. Nos meses de verão a população residente chega a quintuplicar. As visitas domiciliares tiveram início em 9 de outubro de 2000, com os agentes de saúde preenchendo a ficha domiciliar com dados demográficos, e disponibilizando os potes para coleta das amostras de fezes a todos os moradores. No dia seguinte, o material era recolhido e imediatamente encaminhado à Estação de Campo do Programa de Esquistossomose do CPqAM (Centro de Pesquisas Aggeu Magalhães) para diagnóstico parasitológico de fezes pelo método de Kato-Katz, tendo sido examinadas duas lâminas para cada paciente.

A pesquisa malacológica teve duração de dois meses, foi realizada por técnicos do CPqAM e FUNASA, e incluía a busca ativa de focos dos vetores nos quintais, terrenos baldios e nas águas salinizadas do estuário do Rio Ipojuca, ao redor da cidade de Porto de Galinhas. Os caramujos coletados foram conduzidos ao laboratório para verificação de positividade para Schistosoma mansoni.

Os indivíduos com diagnóstico parasitológico positivo para $S$. mansoni receberam o resultado do exame em suas residências. Nessa ocasião, eram feitos agendamentos para a coleta de sangue (sorologia + leucograma) e posterior atendimento médico no posto de saúde local. A definição dos casos agudos tomou por base a sintomatologia, a carga parasitária e os níveis de eosinófilos. A medicação adotada foi a prednisona, na dose de $0,5 \mathrm{mg} / \mathrm{kg}$ para os casos mais sintomáticos e tratamento da esquistossomose com praziquantel na dose única de $60 \mathrm{mg} / \mathrm{kg}$. Crianças com peso abaixo de $30 \mathrm{~kg}$ receberam oxaminiquine xarope na dose de $20 \mathrm{mg} / \mathrm{kg}$.

\section{Resultados}

Os caramujos vetores foram encontrados em abundância nos quintais das residências e terrenos alagadiços. Nas águas salinizadas do estuário do Rio Ipojuca, não foi possível encontrar nenhum exemplar dos caramujos vetores da esquistossomose. A única espécie encontrada foi a Biomphalaria glabrata que exibiu taxa média de infeção por S. mansoni de 48\%. Contudo, foram encontradas conchas de B. glabrata em montes de areia estocados nos armazéns de material de construção, procedentes de rios de diversas regiões do Estado e que são distribuídas para as casas em construção.

O diagnóstico parasitológico realizado em 2.062 pessoas residentes nas áreas que foram inundadas, revelou 662 casos de esquistossomose. A carga parasitária média foi de 152 ovos por grama de fezes. A localidade onde se observou a carga parasitária média mais elevada, assim como as maiores taxas de eosinofilia, foi Merepe III (Tabela 1). Os exames físicos e os resultados dos leucogramas, identificam cerca de $62 \%$ de casos agudos de esquistossomose entre aqueles com exame parasitológico positivo para S. mansoni. A localidade que apresentou maior número de casos agudos (72\%) foi Merepe III. As manifestações clínicas mais usuais foram: dermatite cercariana, cefaléia, tosse seca, dores abdominais, diarréia e febre. O uso da prednisona se fez necessário em $31,6 \%$ dos pacientes devido à gravidade dos sintomas e à intensa eosinofilia. Em Merepe III, 45,3\% dos pacientes necessitaram do pré-tratamento com prednisona. O uso de oxaminiquine líquido só 
Resultados do diagnóstico parasitológico, leucograma e formas clínicas de esquistossomose.

Porto de Galinhas, Pernambuco, dezembro de 2000.

\begin{tabular}{lcccccc}
\hline Localidade & $\begin{array}{l}\text { Pessoas } \\
\text { examinadas }\end{array}$ & $\begin{array}{l}\text { Casos } \\
\text { positivos (\%) }\end{array}$ & $\begin{array}{l}\text { Formas } \\
\text { agudas (\%) }\end{array}$ & $\begin{array}{l}\text { Formas } \\
\text { crônicas (\%) }\end{array}$ & $\begin{array}{l}\text { Carga } \\
\text { parasitária } \\
\text { média }\end{array}$ & Eosinófilos (\%) \\
\hline Merepe III & 292 & 29,45 & 72,15 & 19,80 & 219 & 22,51 \\
Salinas & 771 & 21,91 & 53,80 & 46,20 & 99 & 16,82 \\
Pantanal & 487 & 49,48 & 56,40 & 43,00 & 160 & 14,23 \\
Socó & 462 & 33,98 & 59,70 & 40,30 & 159 & 18,54 \\
Vila de Porto & 50 & 18,00 & 83,30 & 16,60 & 210 & 11,50 \\
Total & 2.062 & 32,10 & 62,20 & 38,60 & 152 & 83,60 \\
\hline
\end{tabular}

foi necessário em 9,35\% da população com menos de nove anos de idade.

\section{Comentários finais}

O vetor responsável pela epidemia em Porto de Galinhas foi a B. glabrata, característico das áreas litorâneas do Estado de Pernambuco. Após dois meses de exaustiva pesquisa malacológica em todas as coleções d'água disponíveis, não foi possível encontrar nenhum exemplar de B. glabrata nas águas salinizadas do estuário do Rio Ipojuca, embora quintais e terrenos estivessem repletos de caramujos infectados. Na segunda quinzena de setembro, ao término da estação chuvosa, as ruas começaram a secar e os criadouros de caramujos ficaram restritos aos quintais, que continuaram semi-alagados durante os três meses subseqüentes.

Os dados de literatura disponíveis referentes à prevalência de esquistossomose e à ocorrência de planorbídeos no Rio Ipojuca (Lucena, 1963) não são recentes, informando que a bacia hidrográfica deste rio é de reconhecida importância epidemiológica na transmissão da esquistossomose em áreas rurais de Pernambuco, onde o único vetor encontrado é a $B$. straminea.

No surto de esquistossomose ocorrido em Porto de Galinhas, a investigação malacológica partiu da hipótese inicial de que estes caramujos teriam sido introduzidos nas ruas e quintais por ocasião das enchentes, trazidos pelas águas do Rio Ipojuca. Esta hipótese poderia ser corroborada se tivessem sido encontradas amostras vivas ou conchas de B. glabrata na pesquisa malacológica realizada nas margens do estuário e no leito do rio, ao longo de $10 \mathrm{~km}$ acima da Vila de Porto. Do mesmo modo, estes moluscos não foram encontrados na vila próxima de Nossa Senhora do Ó, localizada a $12 \mathrm{~km}$ de distância, por onde passa o Rio Ipojuca antes de desaguar em Porto de Galinhas. Estas evidências, aliadas aos depoimentos de moradores locais, e ao fato de terem sido encontradas conchas deste molusco nas areias das casas de materiais de construção, nos fazem presumir que a espécie foi introduzida na cidade de Porto de Galinhas junto com a areia dos aterros realizados nas áreas alagadiças do manguezal. Em algumas destas áreas, mais próximas ao mar, e consideradas nobres pela especulação imobiliária, foram construídos loteamentos para a população de classes média e alta. Outras áreas mais periféricas foram ocupadas caoticamente por famílias de desempregados de várias procedências, transformando-se em favelas.

O estabelecimento de residências nestas áreas exigiu uma quantidade considerável de areia, tanto para aterros como para a preparação das massas utilizadas na construção. Esta areia, procedente de leitos de rios, pode ter sido o veículo que introduziu a espécie $B$. glabrata na localidade. Deste modo, os moluscos puderam se reproduzir abundantemente nos criadouros domiciliares em fundos de quintais, que permanecem alagados por boa parte do ano. A infecção dos caramujos teria se dado a partir de contaminação fecal direta, uma vez que a maioria das casas da favela não possui fossa. Com a enchente, os caramujos foram levados para os bairros de classes média e alta de Porto de Galinhas.

O inquérito epidemiológico revelou que a maioria dos pacientes com sintomatologia foi representada por famílias inteiras de residentes locais, sejam elas de classe média (artesões, proprietários de pousadas e restaurantes) ou 
de baixa renda (pescadores e prestadores de serviços). Estas famílias tiveram exposição diária às cercárias durante cerca de três semanas, até que as ruas e quintais secassem. Durante todo este período foram obrigadas a transitar pelas águas contaminadas em atividades cotidianas.

Alguns veranistas entrevistados mencionaram ter sido infectados naquela ocasião e descreveram sintomatologia típica de esquistossomose aguda. Por ocasião desse inquérito, cerca de 300 residências de veranistas encontravamse desocupadas, perdendo-se assim a oportunidade de registrar um maior número de casos. Pretende-se voltar à localidade para a aplicação de um inquérito de morbidade referida, com vistas a se estimar o porcentual de veranistas infectados neste evento. As localidades

\section{Agradecimentos}

Aos técnicos da Estação de Campo do Programa de Esquistossomose do Centro de Pesquisas Aggeu Magalhães, Fundação Oswaldo Cruz e aos agentes de saúde da Fundação Nacional de Saúde, pela valiosa ajuda nos trabalhos de laboratório e campo. Projeto financiado pelo Programa de Apoio à Pesquisa Estratégica em Saúde (PAPES) da Fundação Oswaldo Cruz. de Merepe e Vila de Porto, onde residem ou veraneiam pessoas de classes média e alta, foram aquelas onde a carga parasitária média foi mais elevada, houve maior porcentual de eosinofilia e a sintomatologia foi mais intensa, o que sugere que estas pessoas nunca tiveram contato com o parasito, estando, portanto, desprovidas de imunidade. Alguns destes pacientes necessitaram de internação diante da intensidade dos sintomas respiratórios e da elevada eosinofilia.

Estudos complementares estão sendo realizados, no sentido de se ampliar o diagnóstico para a compreensão deste evento epidemiológico de significativa magnitude e impacto para os órgãos de saúde pública e para a população afetada pelo agravo.

\section{Referências}

ALMEIDA, Y. M.; SOUZA FILHO, J. V.; BRINGEL, M. J. A.; BARROS Jr., E. A. \& DIAS Jr., F. A., 1991. Movimentos migratórios e a expansão da esquistossomose no Estado do Ceará. Revista do Instituto de Medicina Tropical de São Paulo, 33(Sup. 1):48.

BARATA, C. H.; NETO, H. V. S.; CUNHA, I. C. L.; RODRIGUES Jr., V. \& PRATA, A., 2000. Novo foco de esquistossomose mansoni em sacramento, Alto do Parnaíba, Minas Gerais, Brasil. Revista da Sociedade Brasileira de Medicina Tropical, 33(Sup. 1):379.

BARBOSA, C. S.; GONÇALVES, J. F.; ALBUQUERQUE, Y. \& BARBOSA, F. S., 1998. Urban schistosomiasis in Itamaracá Island, Pernambuco, Brazil: Epidemiological factors involved in the recent endemic process. Memórias do Instituto Oswaldo Cruz, 93:265-266.

BARBOSA, C. S.; PIERI, O. S.; SILVA, C. B. \& BARBOSA, F. S., 2000. Ecoepidemiologia da esquistossomose urbana na ilha de Itamaracá, Pernambuco. Revista de Saúde Pública 34:337-341.

COUTINHO, E. M.; ABATH, F.; BARBOSA, C. S.; MONTENEGRO, S.; TEIXEIRA, K. M. \& DOMINGUES, A. L. C., 1997. Factors involved in S. mansoni infection in rural areas in Northeast Brazil. Memórias do Instituto Oswaldo Cruz, 92:707-715.

LIMA, V. L. C., 1995. A esquistossomose urbana e a heterogeneidade social e epidemiológica do $\mathrm{Mu}$ nicípio de Campinas, São Paulo, Brasil. Cadernos de Saúde Pública, 11:45-56.

LUCENA, D. T., 1963. Planorbídeos transmissores da esquistossomose no Nordeste do Brasil. Revista Brasileira de Malariologia e Doenças Tropicais, 15:13-26.

SILVA, A.; SANTANA, L. B.; JESUS, A. R.; BURATTINI, M. N. \& CARVALHO, E., 2000. Aspectos clínicos de um surto de esquistossomose aguda no Estado de Sergipe, Brasil. Revista da Sociedade Brasileira de Medicina Tropical, 33(Sup. 1):376. 